\title{
Obesity, Smoking, Physical Activity, Hypertension: Models of Stroke Causes in South Sulawesi Province
}

\author{
Obesitas, Merokok, Aktifitas Fisik, Hipertensi: \\ Model Penyebab Kejadian Stroke di Provinsi Sulawesi Selatan
}

\author{
Muhammad Awal ${ }^{1}$, Ashriady $^{2}$, Darwis Durahim ${ }^{3}$, Adriyani Adam** \\ ${ }^{1,3}$ Bagian Fisioterapi, Politeknik Kesehatan Makassar, Makassar \\ ${ }^{2}$ Bagian Kebidanan, Politeknik Kesehatan Mamuju, Mamuju \\ ${ }^{4}$ Bagian Gizi, Politeknik Kesehatan Makassar, Makassar
}

DOI: $10.24252 /$ al-sihah.v13i2.22172

Received: 16 July 2021 / In Reviewed: 20 October 2021 / Accepted: 26 December 2021 / Available online: 30 December 2021 (C) The Authors 2021. This is an open access article under the CC BY-NC-SA 4.0 license

\begin{abstract}
Lifestyle changes have led to an increase in cases of non-communicable diseases in Indonesia, including hypertension and stroke. This research aimed to determine the factor of obesity, smoking behavior, physical activity, and hypertension on the incidence of stroke in South Sulawesi Province. The method of research was analytic observational with a case-control approach. The case group was stroke patients as many as 750 cases and the control group was non-stroke patients as many as 750 cases. Data analysis using Path analysis. The results showed that there was a significant relationship between stroke and hypertension with a path coefficient value of 0.33 , the relationship between physical activity and the incidence of stroke through hypertension with a path coefficient value of 0.13, obesity and the incidence of stroke through hypertension with a path coefficient value of 0, 21, there is a relationship between smoking and the incidence of stroke through hypertension with a path coefficient value of 0.08. Hypertension is a risk factor that directly affects the incidence of stroke compared to other risk factors. however, all of these risk factors can be reduced, especially by doing routine and regular physical activity every day. This research contributed to setting priorities for stroke prevention programs to reduce the incidence of stroke in Indonesia and specifically in South Sulawesi.
\end{abstract}

\section{ABSTRAK}

Perubahan gaya hidup telah menyebabkan peningkatan kasus penyakit tidak menular di Indonesia, termasuk hipertensi dan stroke. Penelitian ini bertujuan untuk mengetahui model faktor obesitas, perilaku merokok, aktifitas fisik dan hipertensi terhadap kejadian stroke di Provinsi Sulawesi Selatan. Metode penelitian yang digunakan adalah observasional analitik dengan pendekatan case control. Kelompok kasus adalah pasien stroke sebanyak 750 kasus dan kelompok kontrol adalah selain pasien stroke sebanyak 750 kasus. Analisis data dengan menggunakan analisis Jalur. Hasil penelitian menunjukkan ada hubungan yang signifikan antara stroke dengan hipertensi dengan nilai koefisien jalur sebesar 0,33 , hubungan aktivitas fisik dengan kejadian stroke melalui hipertensi dengan nilai koefisien jalur sebesar 0,13, obesitas dengan kejadian stroke melalui hipertensi dengan nilai koefisien jalur sebesar 0,21, ada hubungan merokok dengan kejadian stroke melalui hipertensi dengan nilai koefisien jalur sebesar 0,08. Hipertensi merupakan faktor risiko yang langsung berpengaruh terhadap kejadian stroke dibandingkan dengan faktor risiko yang lain, namun semua faktor risiko ini dapat diturunkan terutama dengan melakukan aktivitas fisik rutin dan teratur setiap hari. Penelitian ini berkontribusi dalam menetapkan prioritas program penanggulangan stroke sehingga dapat menurunkan angka kejadian stroke di Indonesia dan di Sulawesi Selatan pada khususnya.

\section{GRAPHICAL ABSTRACT}

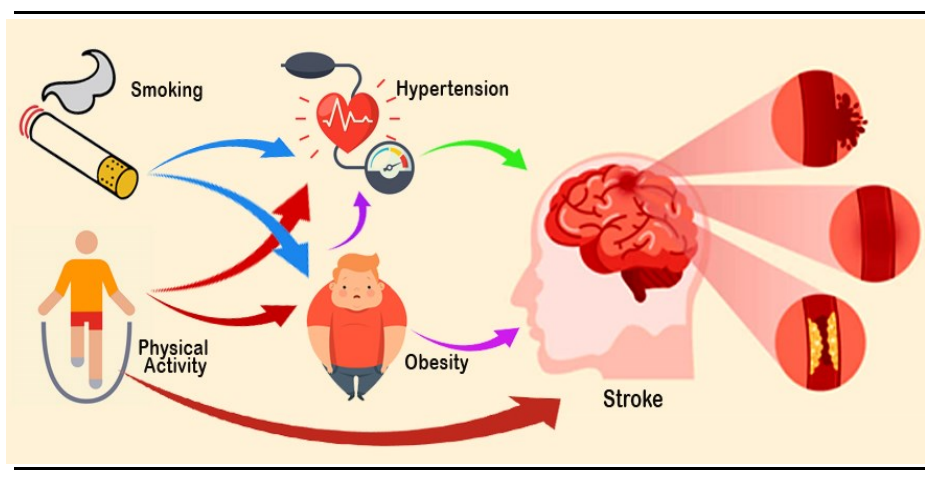

\section{Keyword}

hypertension disease; models of stroke; obesity factors; physical activity; smoking behavior

\section{Kata Kunci:}

aktivitas fisik; faktor obesitas; penyakit hipertensi; model stroke; perilaku merokok

* Correspondence

Jln. Paccerakkang KM. 14 Daya, Biringkanaya,

Kota Makassar

Email: adriyani@poltekkes-mks.ac.id 


\section{PENDAHULUAN}

Kejadian stroke di berbagai dunia telah dikaji secara intensif, termasuk di Indonesia namun pendekatannya lebih banyak mengkaji pada aspek kuratif, faktor risiko secara komprehensif belum banyak dikaji khususnya berbagai faktor yang dapat menyebabkan stroke. Stroke merupakan penyebab kematian terbesar kedua di dunia, dengan angka kematian 6,7 juta (11,9\% dari seluruh kematian) setiap tahunnya. Stroke non hemoragic (ischemic) menyumbang 8090\% dari semua kejadian stroke. Kondisi yang meningkatkan resiko stroke adalah arteriosklerosis, yang merupakan proses inflamasi kronis pada arteri besar dan menengah termasuk di otak (Zhang \& Yang, 2014; Aaby et al., 2017; Nyberg et al., 2018; Virani et al., 2021).

Indonesia merupakan negara dengan jumlah kasus stroke terbanyak di Asia dengan kejadian 8,3 dari 1000 penduduk. Kejadian ini meningkat seiring dengan bertambahnya usia. Secara nasional memperlihatkan stroke merupakan penyebab kematian tertinggi, dengan $15,4 \%$ didapatkan sekitar 750.000, insiden stroke per tahun di Indonesia dan 200.000 diantaranya stroke berulang. Berdasarkan data Riskesdas 2013, prevalensi stroke di Indonesia meningkat dari 8,3 per 1000 populasi pada tahun 2007 menjadi 12,1 per 1000 populasi pada tahun 2013. Sulawesi Selatan merupakan provinsi dengan prevalensi stroke tertinggi dibandingkan dengan provinsi lain di Indonesia berdasarkan terdiagnosis nakes dan gejala tertinggi yaitu sebesar $17,9 \%$, angka tersebut meningkat $10,5 \%$ dari tahun 2007 yaitu sebesar 7,4\% (Benjamin et al., 2018;
Kementerian Kesehatan RI., 2013).

Kejadian stroke ischemic pada perokok beresiko 4 kali lipat. Merokok menyebabkan pengerasan dan penyempitan arteri di seluruh tubuh (termasuk yang ada di otak), sehingga merokok menyebabkan terjadinya aterosklerosis, menurunkan aliran darah, dan menyebabkan darah mudah mengental, meningkatkan pembentukan dan pertumbuhan aneurisma intrakranium (Miller et al., 2017; Nyberg et al., 2018; Prabhakar \& Stewart, 2018; Stewart et al., 2017). Aktivitas fisik kurang dari 3 kali perminggu selama 30 menit setiap kali meningkatkan resiko stroke sekitar 50\% dibanding yang aktif. Aktivitas fisik yang kurang dapat mengakibatkan obesitas dan tekanan darah meningkat, serta bisa terkena diabetes yang semuanya meningkatkan risiko stroke. $\mathrm{Ku}$ rang aktivitas juga menimbulkan aterosklerosis dini serta berbagai penyakit kardiovaskular lain (Feigin \& Krishnamurthi, 2011; Lin et al., 2019; Nyberg et al., 2018; Trigueros et al., 2019).

Beberapa penelitian telah dilakukan untuk menemukan faktor risiko merokok terhadap gangguan kesehatan, seperti Tang et al. (2020) yang menghubungkan kejadian gangguan jantung pada perokok, O'Keeffe et al. (2018) yang mengkorelasikan kanker paru pada perokok, serta Tewatia et al. (2020) yang mengkaji tentang dampak rokok yang memperparah kesehatan penderita tuberkulosis, namun belum banyak peneliti yang mengkaji analisis jalur untuk menghasilkan model risiko merokok pada penyakit komorbid. Pada penelitian ini menggunakan model analisis jalur yang dengan tujuan untuk mengetahui model 


\section{Gambar 1}

Model Analisis Jalur

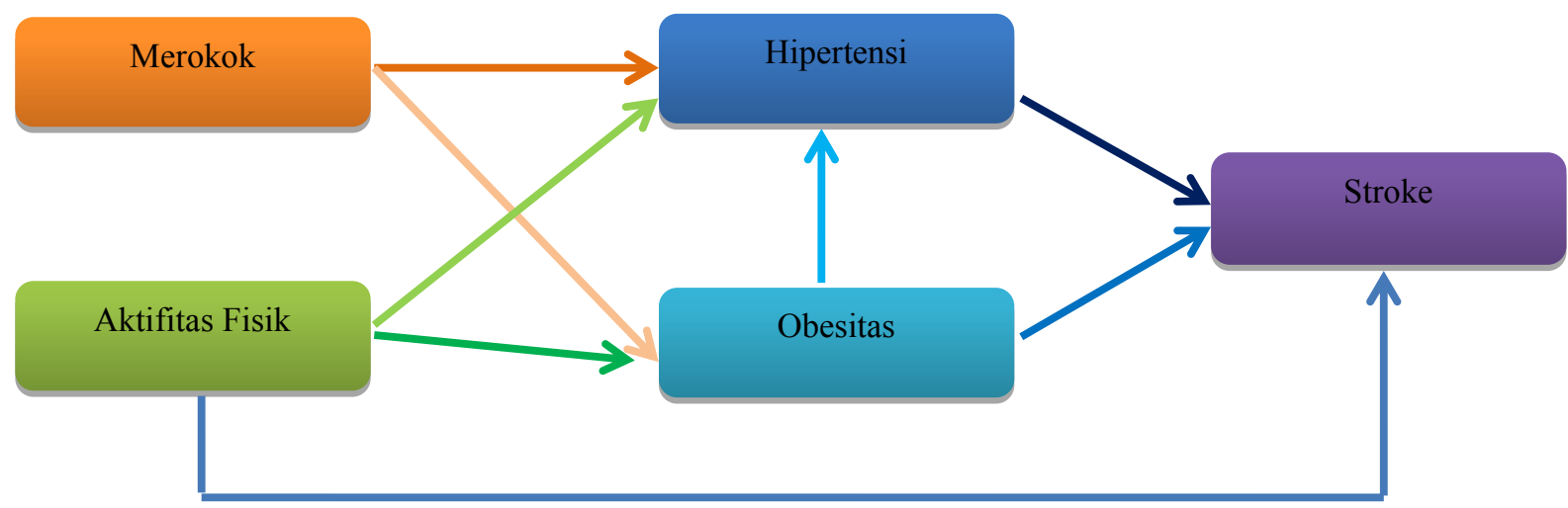

faktor obesitas, perilaku merokok, aktifitas fisik dan hipertensi terhadap kejadian stroke di Provinsi Sulawesi Selatan.

\section{METODE PENELITIAN}

Penelitian dilaksanakan di Sulawesi Selatan dengan menjadikan Rumah Sakit Umum Pusat Dr. Wahidin Sudirohusodo dan dan Rumah Sakit Pendidikan Unhas sebagai tempat penelitian yang dilaksanakan selama 6 Bulan. Dari bulan Maret - Agustus 2017 Pemilihan lokasi karena kedua Rumah Sakit ini merupakan pusat rujukan untuk seluruh Rumah Sakit yang berada di wilayah Provinsi Sulawesi Selatan.

Jenis penelitian ini adalah penelitian observasional analitik dengan desain casecontrol. Kelompok kasus adalah pasien dengan diagnosis stroke dan kelompok kontrol adalah selain penderita stroke. Pasien stroke yang tercatat dalam rekam medik RSUP Dr.Wahidin Sudirohusodo Makassar dan RSP Unhas tahun 2016 2017 yang mempunyai rekam medik yang lengkap sesuai dengan variabel penelitian sebanyak 1500 kasus dan kontrol yang didapat melalui rumus sampel. Data dianalisis dengan menggunakan model analisis jalur yaitu dengan menghubungkan variabel penelitian yang merupakan faktor yang dapat menyebabkan stroke kemudian dibuat model sesuai Gambar 1. Pada penelitian ini sampel kasus diambil dari rekam medik pasien yang di diagnosis stroke yang mempunyai catatan yang lengkap dengan jumlah 750 kasus sementara control diambil dari rekam medik pasien selain kasus stroke dengan jumlah 750 kontrol.

Data yang diambil merupakan data sekunder yang berasal dari rekam medik di RSUP Dr. Wahidin Sudirohusodo Makassar dan dan RSP Unhas,Pengambilan data dengan pengisian lembar observasi dalam bentuk daftar isian, melalui observasi pada rekam medik pasien dengan melihat variabel penelitian. Untuk analisis data, secara umum dengan persentase dan distribusi masing-masing variabel penelitian, dan untuk analisis jalur (Path Analisis) untuk mengetahui pengaruh satu atau lebih dari variabel bebas terhadap variabel terikat. Penelitian ini menggunakan ethical clearance yang dikeluarkan oleh Komite Etik Fakultas Kedokteran Universitas Hasanuddin.Penelitian ini mendapatkan rekomendasi etik dari Komisi Etik Politeknik Kesehatan Makassar No. : 0040 / KEPK- 
Tabel 1

Distribusi Karakteristik Responden

\begin{tabular}{|c|c|c|c|c|c|c|c|}
\hline \multirow{3}{*}{ Karakteristik Responden } & \multicolumn{4}{|c|}{ Stroke } & \multirow{2}{*}{\multicolumn{2}{|c|}{ Total }} & \multirow{3}{*}{$\mathrm{P}$} \\
\hline & \multicolumn{2}{|c|}{ Kasus } & \multicolumn{2}{|c|}{ Kontrol } & & & \\
\hline & $\mathrm{n}$ & $\%$ & $\mathrm{n}$ & $\%$ & $\mathrm{n}$ & $\%$ & \\
\hline \multicolumn{8}{|l|}{ Jenis Kelamin } \\
\hline Laki-Laki & 401 & 53,5 & 372 & 49,6 & 773 & 51,5 & 0,134 \\
\hline Perempuan & 349 & 46,5 & 378 & 50,3 & 727 & 48,5 & \\
\hline \multicolumn{8}{|l|}{ Kelompok umur } \\
\hline $10-19$ & 1 & 1 & 1 & 1 & 2 & 1 & \\
\hline $20-29$ & 16 & 2,1 & 27 & 3,6 & 43 & 2,9 & \\
\hline $30-39$ & 25 & 3,3 & 36 & 4,8 & 61 & 4,1 & \\
\hline $40-49$ & 94 & 12,5 & 91 & 12,1 & 185 & 12,3 & 0,606 \\
\hline $50-59$ & 241 & 32,1 & 238 & 31,7 & 479 & 31,9 & \\
\hline $60-69$ & 224 & 29,9 & 212 & 28,3 & 436 & 29,1 & \\
\hline $70-79$ & 115 & 15,3 & 115 & 15,3 & 230 & 15,3 & \\
\hline$>=80$ & 34 & 4,5 & 30 & 4,0 & 64 & 4,3 & \\
\hline \multicolumn{8}{|l|}{ Pendidikan } \\
\hline Tidak sekolah & 90 & 12,0 & 69 & 9,2 & 159 & 10,6 & \\
\hline SD & 240 & 32,0 & 254 & 33,9 & 494 & 32,9 & \\
\hline SLTP & 84 & 11,2 & 80 & 10,7 & 164 & 10,9 & \\
\hline SLTA & 232 & 30,9 & 251 & 33,5 & 483 & 32,2 & 0,230 \\
\hline Diploma & 18 & 2,4 & 25 & 3,3 & 43 & 2,9 & \\
\hline $\mathrm{S} 1$ & 78 & 10,4 & 68 & 9,1 & 146 & 9,7 & \\
\hline $\mathrm{S} 2$ & 8 & 1,1 & 3 &, 3 & 11 &, 7 & \\
\hline \multicolumn{8}{|l|}{ Pekerjaan } \\
\hline IRT & 234 & 31,2 & 233 & 31,1 & 467 & 31,1 & \\
\hline PNS & 128 & 17,1 & 167 & 22,3 & 295 & 19,7 & \\
\hline Swasta & 99 & 13,2 & 123 & 16,3 & 222 & 14,8 & \\
\hline Wiraswasta & 54 & 7,2 & 12 & 1,6 & 66 & 4,3 & \\
\hline Petani & 68 & 9,1 & 46 & 6,1 & 114 & 7,6 & 0,000 \\
\hline tidak bekerja & 62 & 8,3 & 25 & 3,3 & 87 & 5,8 & \\
\hline Pensiunan & 95 & 12,7 & 131 & 17,5 & 226 & 15,1 & \\
\hline pelajar/mahasiswa & 10 & 1,3 & 13 & 1,7 & 23 & 1,5 & \\
\hline \multicolumn{8}{|l|}{ Status Perkawinan } \\
\hline Menikah & 710 & 94,7 & 706 & 94,1 & 1416 & 94,3 & \\
\hline Belum Menikah & 37 & 4,9 & 42 & 5,6 & 79 & 5,3 & 0,723 \\
\hline Janda & 2 &, 3 & 2 &, 3 & 4 &, 3 & \\
\hline Duda & 1 & 1 & & & 1 & 1 & \\
\hline
\end{tabular}

PTKMKS/ III /2021.

\section{HASIL PENELITIAN}

Hasil penelitian pada Tabel 1 menunjukkan bahwa kejadian stroke lebih tinggi terjadi pada jenis kelamin laki-laki yaitu $53,5 \%$, sedangkan perempuan sebesar $46,5 \%$, pada kelompok umur 50 - 59 tahun sebanyak $32,1 \%$, pada tingkat pendidikan SD yaitu $32,0 \%$, pada jenis pekerjaan ibu rumah tangga yaitu $31,2 \%$, dan status menikah 94,7\%. Berdasarkan uji chi square seperti pada Tabel 1 diketahui bahwa jenis kelamin, kelompok umur, pendidikan dan status perkawinan responden adalah homogen $(p<0,05)$. Untuk hubungan antar variabel dalam penelitian ini berdasarkan hasil analisis jalur sesuai dengan Tabel 2 bahwa terjadinya hipertensi dan stroke menunjukkan bahwa variabel yang mempengaruhi ter- 
Tabel 2

Hasil Analisis Hubungan Antar Variabel dengan terjadinya hipertensi dan stroke

\begin{tabular}{lllcc}
\hline $\begin{array}{c}\text { Variabel inde- } \\
\text { penden }\end{array}$ & & Variabel dependen & $\begin{array}{c}\text { Koefisein Jalur } \\
\text { (standardized) }\end{array}$ & T \\
\hline Merokok & $\ldots \ldots \ldots$ & Obesitas & 0,03 & $0,94^{* *}$ \\
Merokok & $\longrightarrow \ldots$ & Hipertensi & 0,08 & $2,58^{*}$ \\
Aktifitas fisik & $-\ldots$ & Obesitas & 0,00 & $0,11^{* *}$ \\
Aktifitas fisik & & Hipertensi & 0,13 & $3,14^{*}$ \\
Obesitas & & Hipertensi & 0,21 & $8,70^{*}$ \\
Hipertensi & & Stroke & 0,33 & $13,29^{*}$ \\
\hline
\end{tabular}

Note: $*=$ Signifikan; $* *=$ Tidak Signifikan

jadinya hipertensi adalah merokok, aktivitas fisik, dan obesitas, sedangkan faktor penyebab terjadinya stroke adalah hipertensi karena semua variab bermakna maka tidak ada variabel yang dikeluarkan sehingga model penyebab terjadinya hipertensi dan stroke tidak berubah (Boan et al., 2014; Chang et al., 2015; Muraki et al., 2015).

Hasil analisis jalur terhadap terjadinya hipertensi dan stroke sesuai Tabel 2 menunjukkan bahwa variabel yang mempengaruhi terjadinya hipertensi adalah merokok,aktivitas fisik, dan obesitas sedangkan faktor penyebab terjadinya stroke adalah hipertensi. karena semua variabel bermakna maka tidak ada variabel yang dikeluarkan sehingga model penyebab terjadinya hipertensi dan stroke tidak berubah. Tabel 3 menunjukkan bahwa hasil analisis jalur terhadap terjadinya hipertensi menunjukkan bahwa ada pengaruh tidak langsung merokok, Aktifitas fisik dan obesitas dengan terjadinya hipertensi, dan terjadinya stroke dipengaruhi secara tidak langsung oleh hipertensi, merokok, Aktifitas fisik dan obesitas (Gaciong et al., 2013; O'collins et al., 2013; Bushnell et al., 2014).

\section{PEMBAHASAN}

Dari hasil analisis jalur menunjukkan bahwa semua variabel yaitu Obesitas, Merokok, Aktivitas fisik untuk menimbulkan stroke melewati jalur kejadian hipertensi sehingga semua variabel tidak langsung menimbulkan stroke tetapi melalui variabel antara yaitu hipertensi, dimana merokok dan hipertensi mempunyai peluang $38 \%$ untuk terkena stroke, $\mathrm{Ku}$ rang aktivitas fisik dengan hipertensi mempunyai peluang 46\% untuk terkena stroke dan Obesitas dan Hipertensi mempunyai peluang 54\% untuk terkena stroke. Jadi orang yang obesitas dan Hipertensi paling besar peluangnya untuk terkena stroke.

Prevalensi obesitas di kalangan orang dewasa di Amerika Serikat (didefinisikan sebagai indeks massa tubuh (IMT) Telah meningkat dari 13\% menjadi $34 \%$ selama setengah abad terakhir. Tren serupa telah diamati di negara-negara lain meskipun mutlak prevalensi obesitas bervariasi. Sebagai contoh, dibandingkan dengan Amerika Serikat, tingkat obesitas saat ini lebih rendah di Kanada (24\%), Jerman (23\%), dan China (4\%) (Kernan et al., 2013). 
Tabel 3

Hasil Analisis Pengaruh Tidak Langsung Variabel Dengan Terjadinya Stroke

\begin{tabular}{lccc}
\hline \multicolumn{1}{c}{ Variabel } & Variabel antara & Stroke & Besar pengaruh \\
\hline Merokok & Hipertensi & Signifikan & 0,38 \\
Aktifitas fisik & Hipertensi & Signifikan & 0,46 \\
Obesitas & hipertensi & Signifikan & 0,54 \\
Hipertensi & & Signifikan & 0,32 \\
\hline
\end{tabular}

Penelitian yang dilakukan oleh Sjøgren, et al. (2009) terhadap penduduk Denmark menemukan bahwa merokok meningkatkan kejadian penyakit kronis secara signifikan. Merokok bisa mengubah metabolisme kolesterol menjadi aterogenik, dapat memicu peningkatan kolesterol darah serta mengurangi kadar HDL. Merokok memicu peningkatan LDL dan menurunkan kadar HDL dalam darah. Penelitian yang dilakukan Khodamoradi et al. (2021) memaparkan bahwa merokok dapat mengurangi resiko hipertensi namun dapat menyebabkan penurunan HDL. Studi lain dilakukan Jain \& Ducatman (2018) melaporkan bahwa perokok dan mantan perokok memiliki memiliki HDL dan trigliserida yang abnormal serta jumlah kolesterol yang normal Karbon monoksida yang terdapat dalam asap rokok lebih kuat menarik sel darah merah dibanding oksigen, sehingga kapasitas sel darah merah pembawa oksigen ke jantung dan jaringan lainnya menurun. Laporan dari Amerika Serikat menunjukkan insiden penyakit jantung koroner (PJK) dapat diturunkan kurang lebih 24,4\% dengan menghentikan kebiasaan merokok dalam jangka waktu 10 tahun (Chang et al., 2016).

Rokok mengandung senyawa seperti karbon monoksida merupakan salah satu faktor yang dapat memperparah penyakit diabetes melitus. Karbon Monoksida yang akan melekat pada sel darah merah yang kaya oksigen sehingga jumlah oksigen yang dibawa darah menjadi berkurang. Akibatnya jantung, otot dan seluruh tubuh kekurangan oksigen. Efek ini diperkirakan lebih nyata pada penderita diabetes yang mempunyai risiko tinggi terhadap masalah sirkulasi darah. Perilaku merokok juga dapat membuat darah mudah menggumpal sehingga meningkatkan resiko tersumbatnya arteri, yang berakibat lanjut bisa terkena serangan jantung ataupun stroke (Bousser, 2012).

Stroke dapat dicegah dengan meningkatkan aktivitas fisik, misalnya lari, jalan, bersepeda, berenang atau berkebun. Aktivitas fisik harus ditingkatkan terutama dalam waktu senggang untuk menurunkan risiko stroke. Karena orang yang inaktivitas fisik memiliki hampir 50\% peningkatan risiko terkena stroke dibanding dengan mereka yang aktif. Aktifitas fisik yang kurang sangat berkaitan dengan peningkatan berat badan, tekanan darah, serta berkaitan dengan diabetes, yang semuanya merupakan faktor risiko stroke (Benjamin et al., 2019; Boan et al., 2014; Helms et al., 2014; Ma, 2014).

Aktivitas fisik memiliki potensi manfaat pasca mengalami stroke atau cedera tulang belakang (SCI), terutama dalam meningkatkan efisiensi dan kapasitas fungsional dalam aktivitas sehari-hari. Saat 
ini, banyak orang yang bisa mendapatkan manfaat dari aktivitas fisik dapat secara rutin yang berkaitan dengan kapasitas fungsional dan kepedulian terhadap bahaya kesehatan (Wisløff, 2014; Zehr, 2011)

Melakukan aktivitas fisik akan menghindarkan kita dari berbagai penyakit, dengan melakukan aktifitas fisik yang memadai kita dapat menekan meningkatnya kadar gula darah, kadar kolesterol, dan menghindari obesitas serta menguatkan jantung. Dimana semua itu merupakan faktor risiko stroke. Sehingga dengan demikian dengan melakukan aktifitas fisik yang memadai kita dapat terhindar dari stroke (Kammerlind et al., 2016).

Aktivitas fisik bukan semata-mata melakukan olahraga, dengan melakukan kegiatan berkebun, berjalan atau bersepeda ke tempat kerja, ke mesjid, ke pasar atau tempat-tempat lainnya akan membakar kalori yang ada dalam tubuh sehingga menghindari penumpukan dalam darah khususnya pada dinding pembuluh darah . Bahkan ada orang bijak yang mengatakan setiap langkah kaki anda akan menghindarkan anda dari penyakit jantung dan stroke. Akan lebih baik kalau bisa meluangkan waktu untuk melakukan olahraga 3-4 kali seminggu selama 30-45 menit, tentunya akan menyehatkan tubuh dan menghindarkan tubuh dari penyakit-penyakit yang membahayakan (Liao et al., 2015).

\section{KESIMPULAN}

Penelitian ini memberikan kontribusi yang sangat besar dalam upaya pencegahan stroke. Model matematik yang paling besar menyebabkan stroke adalah obesitas dan hipertensi. Sedangkan aktivitas fisik yang kurang dan menderita Hipertensi berada di urutan kedua untuk terkena stroke. Dengan memahami model matematik ini maka akan menjadi informasi yang sangat penting dalam upaya pencegahan stroke khususnya dalam bidang public health. Obesitas, hipertensi dan aktivitas fisik merupakan faktor resiko yang dapat dicegah sedini mungkin melalui perilaku hidup sehat. Dengan menggalakkan promosi kesehatan tentang pencegahan faktor resiko secara terarah, rutin, berkelanjutan dan fokus pada informasi tentang obesitas, hipertensi dan fisik diharapkan dapat menurunkan prevalensi kejadian stroke. Adapun keterbatasan penelitian ini adalah belum terbentuknya model yang tepat dalam mereduksi risiko Stroke dengan demikian penelitian ini dapat ditindaklanjuti dengan penelitian model intervensi faktor risiko Stroke.

\section{DAFTAR PUSTAKA}

Aaby, A., Friis, K., Christensen, B., Rowlands, G., \& Maindal, H. T. (2017). Health literacy is associated with health behaviour and selfreported health: A large population-based study in individuals with cardiovascular disease. European journal of preventive cardiology, 24(17), 1880-1888. https:// doi.org/10.1177/2047487317729538

Benjamin, E. J., Muntner, P., Alonso, A., Bittencourt, M. S., Callaway, C. W., Carson, A. P., Das, S. R. (2019). Heart disease and stroke statistics-2019 update: a report from the American Heart Association. Circulation, 139(10), e56-e528. https:// doi.org/10.1161/CIR.0000000000000659

Benjamin, E. J., Virani, S. S., Callaway, C. W., Chamberlain, A. M., Chang, A. R., Cheng, S., Deo, R. (2018). Heart disease and stroke statistics-2018 update: a report from the American Heart Association. Circulation, 137(12), e67-e492. https://doi.org/10.1161/ 


\section{CIR.0000000000000558}

Boan, A. D., Egan, B. M., Bachman, D. L., Adams, R. J., Feng, W., Jauch, E. C., Lackland, D. T. (2014). Antihypertensive Medication Persistence $1 \square$ Year Post $\square$ Stroke Hospitalization. The Journal of Clinical Hypertension, 16(12), 869-874. https:// doi.org/10.1111/jch.12424

Bousser, M. G. (2012). Stroke prevention: an update. Front Med, 6(1), 22-34. https:// doi.org/10.1007/s11684-012-0178-6

Bushnell, C., Arnan, M., \& Han, S. (2014). A new model for secondary prevention of stroke: transition coaching for stroke. Frontiers in neurology, 5, 219. https://doi.org/10.3389/ fneur.2014.00219

Castelli, W. (1988). Cholesterol and lipids in the risk of coronary artery disease--the Framingham Heart Study. The Canadian journal of cardiology, 4, 5A-10A. https://europepmc.org/ article/med/3179802

Chang, S., Kim, H., Kim, V., Lee, K., Jeong, H., Lee, J.-H., Ko, E. (2016). Association Between Smoking and Physician-Diagnosed Stroke and Myocardial Infarction in Male Adults in Korea. Int J Environ Res Public Health, 13(2), 158. https://doi.org/10.3390/ ijerph13020158

Chang, W. H., Shin, Y.-I., Lee, S.-G., Oh, G.-J., Lim, Y. S., \& Kim, Y.-H. (2015). Characteristics of inpatient care and rehabilitation for acute first-ever stroke patients. Yonsei medical journal, 56(1), 262-270. https:// doi.org/10.3349/ymj.2015.56.1.262

Feigin, V. L., \& Krishnamurthi, R. (2011). Stroke prevention in the developing world. Stroke, 42(12), 3655-3658. http://doi.org/10.1161/ strokeaha. 110.596858

Gaciong, Z., Siński, M., \& Lewandowski, J. (2013). Blood pressure control and primary prevention of stroke: summary of the recent clinical trial data and meta-analyses. Current hypertension reports, 15(6), 559-574. https://doi.org/10.1007/s11906-013-0401-0

Helms, T. M., Duong, G., Zippel-Schultz, B., Tilz, R. R., Kuck, K.-H., \& Karle, C. A. (2014). Prediction and personalised treatment of atrial fibrillation-stroke prevention: consolidated position paper of CVD professionals. EPMA Journal, 5(1), 1-7. https:// doi.org/10.1186/1878-5085-5-15
Jain, R. B., \& Ducatman, A. (2018). Associations between smoking and lipid/lipoprotein concentrations among US adults aged $\geq 20$ years. Journal of circulating biomarkers, 7 , 1849454418779310. https://doi.org/10.1186/ s12889-020-08809-Z

Kammerlind, A.-S. C., Bravell, M. E., \& Fransson, E. I. (2016). Prevalence of and factors related to mild and substantial dizziness in community-dwelling older adults: a crosssectional study. BMC Geriatr, 16(1), 159. https://doi.org/10.1186/s12877-016-0335-x

Kernan, W. N., Inzucchi, S. E., Sawan, C., Macko, R. F., \& Furie, K. L. (2013). Obesity: a stubbornly obvious target for stroke prevention. Stroke, 44(1), 278-286. https:// doi.org/10.1161/STROKEAHA.111.639922

Kernan, W. N., Inzucchi, S. E., Sawan, C., Macko, R. F., \& Furie, K. L. (2013). Obesity: a stubbornly obvious target for stroke prevention. Stroke, 44(1), 278-286. http:// doi.org/10.1161/strokeaha.111.639922

Khodamoradi, F., Nazemipour, M., Mansournia, N., Yazdani, K., Khalili, D., \& Mansournia, M. A. (2021). The effects of smoking on metabolic syndrome and its components using causal methods in the Iranian population. International Journal of Preventive Medicine, 12. https://dx.doi.org/10.4103\% 2Fijpvm.ijpvm_45_21

Liao, L.-R., Ng, G. Y., Jones, A. Y., Chung, R. C., \& Pang, M. Y. (2015). Effects of vibration intensity, exercise, and motor impairment on leg muscle activity induced by whole-body vibration in people with stroke. Physical therapy, 95(12), $1617 . \quad$ https:// doi.org/10.2522/ptj.20140507

Lin, A. W., Kazemi, M., Jarrett, B. Y., Vanden Brink, H., Hoeger, K. M., Spandorfer, S. D., \& Lujan, M. E. (2019). Dietary and physical activity behaviors in women with polycystic ovary syndrome per the new international evidence-based guideline. Nutrients, 11(11), 2711. https://doi.org/10.3390/nu11112711

Ma, H. T. (2014). A blood pressure monitoring method for stroke management. BioMed research international, 2014. https:// doi.org/10.1155/2014/571623

Miller, V., Mente, A., Dehghan, M., Rangarajan, S., Zhang, X., Swaminathan, S., Lear, S. (2017). Fruit, vegetable, and legume intake, and cardiovascular disease and deaths in 18 
countries (PURE): a prospective cohort study. The Lancet, 390(10107), 2037-2049. https://doi.org/10.1016/S0140-6736(17) 32253-5

Muraki, I., Wu, H., Imamura, F., Laden, F., Rimm, E. B., Hu, F. B., Q. (2015). Rice consumption and risk of cardiovascular disease: results from a pooled analysis of 3 US cohorts. The American journal of clinical nutrition, 101(1), 164-172. https:// doi.org/10.3945/ajen.114.087551

Nyberg, S. T., Batty, G. D., Pentti, J., Virtanen, M., Alfredsson, L., Fransson, E. I., Knutsson, A. (2018). Obesity and loss of disease-free years owing to major non-communicable diseases: a multicohort study. The lancet Public health, 3(10), e490-e497. https:// doi.org/10.1016/S2468-2667(18)30139-7

O’Keeffe, L. M., Taylor, G., Huxley, R. R., Mitchell, P., Woodward, M., \& Peters, S. A. (2018). Smoking as a risk factor for lung cancer in women and men: a systematic review and meta-analysis. BMJ open, $8(10)$, $\mathrm{e} 021611$. bmjopen-2018-021611

O'collins, V. E., Donnan, G. A., Macleod, M. R., \& Howells, D. W. (2013). Hypertension and experimental stroke therapies. Journal of Cerebral Blood Flow \& Metabolism, 33(8), 1141-1147. https://doi.org/10.1038\% 2Fjcbfm.2013.88

Prabhakar, C. R. K., \& Stewart, R. (2018). Physical activity and mortality in patients with stable coronary heart disease. Current opinion in cardiology, 33(6), 653-659. http:// doi.org/10.1097/HCO.0000000000000563

Kementerian Kesehatan RI. (2013). Penyajian Pokok-Pokok Hasil Riset Kesehatan Dasar 2013.

Sjøgren, P., Ekholm, O., Peuckmann, V., \& Grønbæk, M. (2009). Epidemiology of chronic pain in Denmark: an update. European Journal of Pain, 13(3), 287-292. https://doi.org/10.1016/

j.ejpain.2008.04.007

Stewart, R. A., Held, C., Hadziosmanovic, N., Armstrong, P. W., Cannon, C. P., Granger, C.
B., Lonn, E. (2017). Physical activity and mortality in patients with stable coronary heart disease. Journal of the American College of Cardiology, 70(14), 1689-1700. https://doi.org/10.1016/j.jacc.2017.08.017

Tang, R., Yang, S., Liu, W., Yang, B., Wang, S., Yang, Z., \& He, Y. (2020). Smoking is a risk factor of coronary heart disease through HDL-C in Chinese T2DM patients: a mediation analysis. Journal of Healthcare Engineering, $2020.2 \mathrm{https} / /$ doi.org/10.1155/2020/8876812

Tewatia, P., Kaushik, R. M., Kaushik, R., \& Kumar, S. (2020). Tobacco smoking as a risk factor for tuberculous pleural effusion: a casecontrol study. Global health, epidemiology and genomics, 5. https://doi.org/10.1017/ gheg.2020.1

Trigueros, R., Mínguez, L. A., González-Bernal, J. J., Jahouh, M., Soto-Camara, R., \& Aguilar -Parra, J. M. (2019). Influence of teaching style on physical education adolescents' motivation and health-related lifestyle. $\mathrm{Nu}$ trients, 11(11), $2594 . \quad \mathrm{https}: / /$ doi.org/10.3390/nu11112594

Virani, S. S., Alonso, A., Aparicio, H. J., Benjamin, E. J., Bittencourt, M. S., Callaway, C. W., Delling, F. N. (2021). Heart disease and stroke statistics-2021 update: a report from the American Heart Association. Circulation, 143(8), e254-e743. https:// doi.org/10.1161/CIR.0000000000000950

Wisløff, T., Hagen, G., \& Klemp, M. (2014). Economic evaluation of warfarin, dabigatran, rivaroxaban, and apixaban for stroke prevention in atrial fibrillation. Pharmacoeconomics, 32(6), 601-612. https:// doi.org/10.1007/s40273-014-0152-z

Zehr, E. P. (2011). Evidence-based risk assessment and recommendations for physical activity clearance: stroke and spinal cord injury. Appl Physiol Nutr Metab, 36 Suppl 1, S214 -231. https://doi.org/10.1139/h11-055

Zhang, L., \& Yang, L. (2014). Anti-inflammatory effects of vinpocetine in atherosclerosis and ischemic stroke: a review of the literature. Molecules, 20(1), 335-347. https:// doi.org/10.3390/molecules20010335 